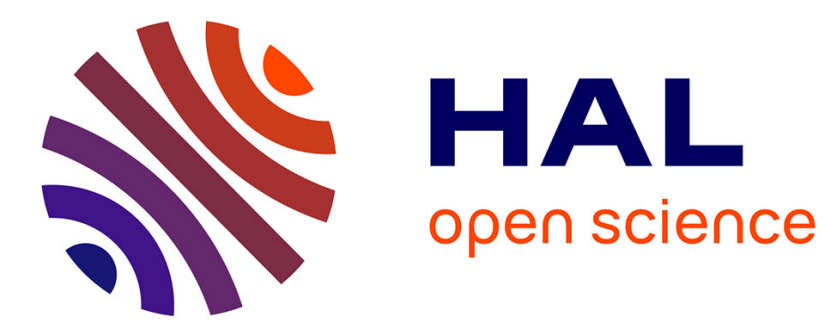

\title{
Evaluation of Design for Reliability Techniques in Embedded Flash Memories
}

\author{
Benoît Godard, Jean-Michel Daga, Lionel Torres, Gilles Sassatelli
}

\section{To cite this version:}

Benoît Godard, Jean-Michel Daga, Lionel Torres, Gilles Sassatelli. Evaluation of Design for Reliability Techniques in Embedded Flash Memories. DATE: Design, Automation and Test in Europe, Apr 2007, Nice, France. pp.1593-1598, 10.1109/DATE.2007.364529 . lirmm-00179951

\section{HAL Id: lirmm-00179951 https://hal-lirmm.ccsd.cnrs.fr/lirmm-00179951}

Submitted on 11 Dec 2007

HAL is a multi-disciplinary open access archive for the deposit and dissemination of scientific research documents, whether they are published or not. The documents may come from teaching and research institutions in France or abroad, or from public or private research centers.
L'archive ouverte pluridisciplinaire HAL, est destinée au dépôt et à la diffusion de documents scientifiques de niveau recherche, publiés ou non, émanant des établissements d'enseignement et de recherche français ou étrangers, des laboratoires publics ou privés. 


\title{
Evaluation of Design for Reliability Techniques in Embedded Flash Memories
}

\author{
Benoît Godard ${ }^{1,2}$, Jean-Michel Daga ${ }^{1}$, Lionel Torres ${ }^{2}$, Gilles Sassatelli ${ }^{2}$ \\ ${ }^{1}$ Libraries and Design Tools Department - Embedded Non-Volatile Memory Group \\ ATMEL Rousset - 13106 Rousset Cedex, France \\ benoit.godard, jean-michel.daga@rfo.atmel.com \\ ${ }^{2}$ Laboratoire d'Informatique, de Robotique et de Microélectronique de Montpellier - LIRMM \\ Université de Montpellier II / UMR5506 CNRS \\ 161, rue Ada - 34392 Montpellier Cedex 5, France \\ torres, sassatelli@lirmm.fr
}

\begin{abstract}
Non-volatile Flash memories are becoming more and more popular in Systems-on-Chip (SoC). Embedded Flash (eFlash) memories are based on the well-known floatinggate transistor concept. The reliability of such type of technology is a growing up issue for embedded systems; endurance and retention are of course the main features to analyze. To enhance memory reliability current eFlash memories designs use techniques such as Error Correction Code (ECC), Redundancy or Threshold Voltage $\left(V_{T}\right)$ Analysis. In this paper, a memory model to evaluate the reliability of eFlash memory arrays under distinct enhancement schemes is developed.
\end{abstract}

\section{Introduction}

Different types of memory can be embedded in a SoC as SRAM, DRAM, EEPROM and Flash. The increased use of portable electronic devices produces a high demand for eFlash memories. eFlash memories exhibit low power characteristics and some security features (lock bits). In addition, these memories allow In Situ Programming (ISP), resulting in very flexible solutions for code development and updates. In parallel with the recent market evolution, SoCs with embedded memories are facing technological issues due to reliability and chip yield. An increasing silicon area is dedicated to memories and storage elements. The Semiconductor Industry Association (SIA) confirms this trend [1] forecasting that memory content will approach $94 \%$ of a SoC silicon area by 2015 . As a result, memory reliability will be the main detractor of the SoC reliability. Additional constraints and reliability objectives may be added to SoCs in order to cover applications such as automotive, aeronautic or biomedical. Manufacturers should borrow specific methods and design solutions to certify defect-free devices.

Error Correcting Codes (ECC) are the most popular method to prevent memories from online random errors. Some parity bits are stored with information bits. Depending on the adopted ECC scheme, a certain number of errors can be detected and corrected. To enhance yield, designers choose row and/or column redundancy. During the test production phase, defective memory elements are disconnected and replaced with error-free redundancy elements. In SoC context, Built-in Self Repair (BISR) has been realized successfully [2]. Throughout the years, these methods have been mixed. Architectures combining ECC and redundancy for yield enhancement [3] [4], and/or reliability enhancement [5] [6] have been developed.

Additionally, Flash memories could be considered as analog memories that allow specific reliability enhancement methods. The mainstream operation is based on the floating gate concept on which charges can be stored or removed by high voltage biasing. It results in a shift of the memory cell threshold voltage $\left(\mathrm{V}_{\mathrm{T}}\right)$. During a read operation, the modulation of the biasing conditions allows $\mathrm{V}_{\mathrm{T}}$ level analysis. Bits whose charge levels are weak can be detected [7]. A cell refreshing scheme [8] and an error detection/correction scheme [9] based on the $\mathrm{V}_{\mathrm{T}}$ level analysis have already been proposed.

In literature, architecture reliability evaluations are usually performed with a constant failure rate reflecting the SRAM cell reliability. Charge loss and cycling degradations are not taken into account even if multiple models for Flash reliability prediction exist [10], [11]. In this paper, we compare different methods to enhance Flash reliability using ECC, online redundancy, and $\mathrm{V}_{\mathrm{T}}$ analysis. For this purpose, a memory array model using the compact model exposed in [10] has been developed. The aim of this work is to help designers to choose the most efficient 
reliability scheme to implement depending on the technology, memory architecture and reliability objective.

The rest of the paper is organized as follow. In section 2 , the cell reliability model is exposed. Next, in section 3 , we describe the concept of cell- $\mathrm{V}_{\mathrm{T}}$ repartition in a word and we introduce reliability enhancement methodologies in section 4. Results and discussion on these reliability techniques are presented in section 5. Finally, in section 6, we conclude this paper and introduce our future work.

\section{Cell reliability modeling}

When electrons are stored in the floating gate, the memory cell has a high $\mathrm{V}_{\mathrm{T}}$. The cell is erased. When electrons are removed from the floating gate, the memory cell has a low $\mathrm{V}_{\mathrm{T}}$. The cell is written. The threshold voltage value of the cell is directly related to the quantity of electrons stored in the floating gate referred as $\mathrm{Q}_{\mathrm{FG}}$ by:

$$
V_{T}=V_{T 0}+\frac{Q_{F G}}{C}
$$

where, $\mathrm{C}, \mathrm{V}_{\mathrm{T} 0}$ are the equivalent capacitance of the floating gate and the virgin threshold voltage, respectively. $\mathrm{Q}_{\mathrm{FG}} / \mathrm{C}$ is also the floating gate potential $\mathrm{V}_{\mathrm{FG}}$. By convention, erased and written cells correspond to the logic value " 1 " and the logic value " 0 ".

Floating gate reliability is covered by two aspects: endurance and retention. Endurance is the memory cell ability to keep good physical characteristics so as to be usable even after multiple write/erase cycles. Retention is the cell ability to retain information throughout time since the last writing operation. Manufacturers targets are typically $10^{5}$ cycles in endurance and 10 years in retention.

From a functional point of view, during the memory life, $\mathrm{V}_{\mathrm{T}}$ are distributed over two populations, one for cells with high $\mathrm{V}_{\mathrm{T}}$ (logic value "1"), and another for cells with low $\mathrm{V}_{\mathrm{T}}$ (logic value " 0 "). Because of charge leakage mechanism, distributions drift with time, " 1 " and " 0 " tends to opposite values and becomes weak or erroneous. In the rest of the paper, only one distribution that goes from high $\mathrm{V}_{\mathrm{T}}$ values (erased cells) to low $\mathrm{V}_{\mathrm{T}}$ values is considered. As shown in the figure 1, the charge leakage mechanism can be modeled by a capacitor being discharged by a source through a thin oxide. The fundamental expression linking threshold voltage with leakage current is derived from (1) and expressed by:

$$
\frac{d V_{T}}{d t}=-\frac{I_{L}}{C}
$$

where, $\mathrm{I}_{\mathrm{L}}$ is the charge leakage current.

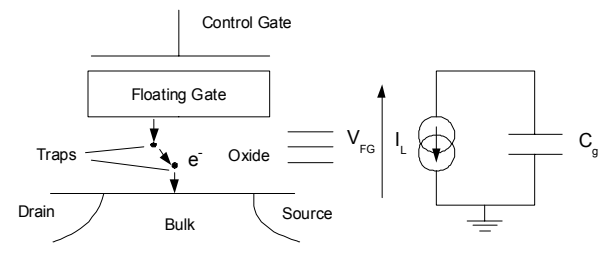

Figure 1 - Defective Flash cell and equivalent cell model
The modeling of the leakage current $I_{L}$ is still a big issue. When low electrical fields are applied to the oxide, conduction mechanisms are not well known. The current leakage is extremely low and difficult to measure accurately. So, the conduction mechanism is usually chosen by using empirical assumptions depending on experimental observations and not on an accurate knowledge of the conduction mechanism. The main retention issues are related to the Stress-Induced Leakage Current (SILC) that becomes predominant when tunnel oxide is thinned. With high field stress used for programming, properties of the insulating layers are degraded. SILC seems to be due to some Trap-Assisted Tunneling effect (TAT) [12]. Multiple models have been developed to describe the SILC phenomenon. The percolation model [12] seems a good way to explain the underlying physical phenomenon.

In our case, the compact model developed in [10] based on an exponential I-V characteristic is used. In this model, $\mathrm{V}_{\mathrm{T}}$ variation between cells is explained by parameters modulation that acts as $\mathrm{V}_{\mathrm{T}}$-shift of the cell threshold distribution. As in [10], the following assumptions on the $\mathrm{V}_{\mathrm{T}}$ evolution are made:

- $\mathrm{V}_{\mathrm{T}}$ drift is independent of the initial $\mathrm{V}_{\mathrm{T}}$ value,

- $\mathrm{V}_{\mathrm{T}}$ drift is linear with the logarithm of the time,

- $\mathrm{V}_{\mathrm{T}}$ drift is linear with the logarithm of the number of write/erase cycles,

- $\mathrm{V}_{\mathrm{T}}$ drift is linear with the inverse of the temperature,

- The ratio of cells below a given $\mathrm{V}_{\mathrm{T}}$ is exponentially distributed.

The resulting reliability modeling determines the probability that cell threshold is higher than a voltage limit $V_{\text {Limit }}$ depending on constants $c_{0}, \mathrm{c}_{1}, c_{2}, c_{3}, c_{4}$ and variables such as time $t$, number of cycles $n_{\text {cycles }}$ and temperature $T$ :

$$
\begin{aligned}
& R_{\text {Normal }}=p\left(V_{T}>V_{\text {Limit }}\right)=f\left(t, n_{\text {cycles }}, T, V_{\text {Limit }}\right) \\
& \ln \left(-\ln \left(1-R_{\text {Normal }}\right)=c_{0}+c_{1} \cdot V_{\text {Limit }}+c_{2} \cdot \ln (t)+c_{3} \ln \left(n_{\text {cycles }}\right)+c_{4} \cdot \frac{1}{T}\right.
\end{aligned}
$$

where, constant $\mathrm{c} 0, \mathrm{c} 1, \mathrm{c} 2, \mathrm{c} 3, \mathrm{c} 4$ are determined from experimental results.

Moreover, erratic bits are considered. The erratic behavior is a floating gate specific issue that usually affects a ratio of cells randomly distributed in an array. For these bits, the threshold voltage may evolve by steps throughout time. These bits are at the root of reliability loss because they cannot be detected during the test production phase: even if a memory has successfully passed tests, it may be defective due to erratic cells. The underlying phenomenon is not known but some explanations have been proposed. Bi-stable traps in the oxide would create a TAT effect. For a ratio of the memory life $\alpha_{\mathrm{ON}}$, these traps would be in an $\mathrm{ON}$ state, adding an additional current leakage $\mathrm{I}_{\mathrm{ON}}$ in the model. The rest of the time, traps would be in an OFF state. This effect is taken into account adding the constant term $c_{0}$ ' to (4):

$\ln \left(-\ln \left(1-R_{\text {Erratic }}\right)=c_{0}+c_{0}{ }^{\prime}+c_{1} \cdot V_{\text {Limit }}+c_{2} \cdot \ln (t)+c_{3} \ln \left(n_{\text {cycles }}\right)+c_{4} \cdot \frac{1}{T}\right.$ 
Erratic bits and normal bits are thus part of two independent distributions. The combination of (4) and (5) gives the reliability for one cell:

$$
R_{\text {cell }}=\alpha \cdot R_{\text {Erratic }}+(1-\alpha) \cdot R_{\text {Normal }}
$$

where, $\alpha$ represents the ratio of erratic bits in a population. By the way, this expression depends on $t$, $n_{\text {cycles }}, T$ and $V_{\text {Limit }}$. In our model, the ageing of normal bits is responsible for the normal memory wear-out, whereas, erratic bits are abnormally increasing the in-line failure rate at the beginning of the memory life.

\section{Cell- $V_{T}$ repartition in a word}

The figure 2 is composed of three $\mathrm{V}_{\mathrm{T}}$ limits: a low voltage value $V_{L}$, a nominal voltage value $V_{N}$ and a high voltage value $\mathrm{V}_{\mathrm{H}}$. When a read operation is performed, a $\mathrm{V}_{\mathrm{T}}$ limit is chosen. Bits with $\mathrm{V}_{\mathrm{T}}$ higher than this limit will correspond to logic value "1". In the same way, bits with $\mathrm{V}_{\mathrm{T}}$ lower than this limit will correspond to logic value " 0 ". We can note that selecting a $V_{T}$ limit is equivalent to perform a read with a particular biasing of the cell control gate.

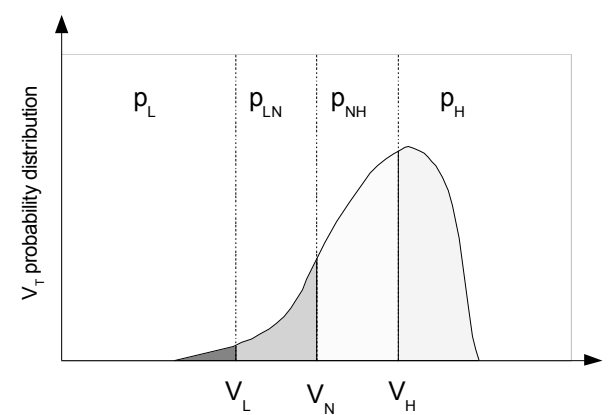

\section{Figure $2-V_{T}$ probability distribution with $V_{T}$} limits

As mentioned in the previous section, only erase operations are considered here. After a write/erase cycle, all the $\mathrm{V}_{\mathrm{T}}$ distribution is shifted towards high $\mathrm{V}_{\mathrm{T}}$ values. But, with time, the distribution drifts to lower values as illustrated in the figure 2. Then, the $\mathrm{V}_{\mathrm{T}}$ of each bit in a word is located in one of four $\mathrm{V}_{\mathrm{T}}$ slices with a certain probability as shown in table 1 . In this table, notions of error bits and weak bits are also defined.

\begin{tabular}{|c|c|c|}
\hline Slice & Type & $\begin{array}{c}\text { Corresponding } \\
\text { probability }\end{array}$ \\
\hline $\mathbf{V}_{\mathbf{T}}>\mathbf{V}_{\mathbf{H}}$ & good bits & $p_{H}=R_{\text {cell }}\left(V_{H}\right)$ \\
\hline $\mathbf{V}_{\mathbf{T}} \in \cdot\left[\mathbf{V}_{\mathbf{N}}, \mathbf{V}_{\mathbf{H}}\right]$ & weak good bits & $p_{N H}=R_{\text {cell }}\left(V_{N}\right)-R_{\text {cell }}\left(V_{H}\right)$ \\
\hline $\mathbf{V}_{\mathbf{T}} \in \cdot\left[\mathbf{V}_{\mathbf{L}}, \mathbf{V}_{\mathbf{N}}\right]$ & weak failing bits & $p_{L N}=R_{\text {cell }}\left(V_{L}\right)-R_{\text {cell }}\left(V_{N}\right)$ \\
\hline $\mathbf{V}_{\mathbf{T}}<\mathbf{V}_{\mathbf{L}}$ & hard failing bits & $p_{L}=1-R_{\text {cell }}\left(V_{L}\right)$ \\
\hline
\end{tabular}

\section{Table 1 - Bits convention and associated probabilities}

To know the efficiency of a reliability scheme, the cells $\mathrm{V}_{\mathrm{T}}$ repartition in a word must be considered. In a word composed of $N_{\text {Cells }}$, the probability of having respectively
$N_{L}, N_{L N}, N_{N H}, N_{H}$ bits in slices $1,2,3$ and 4 is described by a multinomial repartition [14]:

$$
p_{w}\left(N_{L}, N_{L N}, N_{N H}, N_{H}\right)=\frac{N \text { cells }}{N_{L} ! N_{L N} ! N_{N H} ! N_{H} !} \cdot p_{L}^{N_{L}} \cdot p_{L N}{ }^{N_{L V}} \cdot p_{N H}{ }_{N H H} \cdot p_{H}{ }^{N_{H}}
$$

where, $N_{\text {Cells }}=N_{L}+N_{L N}+N_{N H}+N_{H}$.

In the rest of the paper, the $\mathrm{V}_{\mathrm{T}}$ limit is always $\mathrm{V}_{\mathrm{N}}$ when a read is performed. However, this $V_{T}$ limit is changed during a $\mathrm{V}_{\mathrm{T}}$ analysis. Indeed, the $\mathrm{V}_{\mathrm{T}}$ analysis is the process that detects and locates weak bits in a word i.e. bits that have their $\mathrm{V}_{\mathrm{T}}$ in the slice $\left[\mathrm{V}_{\mathrm{L}}, \mathrm{V}_{\mathrm{H}}\right]$. This operation is carried out by two read operations choosing successively $V_{L}$ and $\mathrm{V}_{\mathrm{H}}$ as $\mathrm{V}_{\mathrm{T}}$ limits. Then, weak bits locations are found making a bitwise comparison of read operation's results. Logic values "1" will reveal weak bits.

\section{Reliability enhancement methods}

\subsection{Array modeling}

Figure 3 represents a memory array. It implements additional bits for an error detection/correction system and spare rows for an on-line repair system. Here, column redundancy has not been considered. Indeed, Flash are page-oriented during write/erase operations. These operations are time-consuming (few ms). To replace an entire column with redundancy, all pages of the array should be erased and written back in order to modify only one bit position. This on-line repair process is not realistic because the memory will not be available for a few seconds depending on the depth of the array. For instance, if the replacement of a bit position takes $4 \mathrm{~ms}$ and the array has 1024 pages, the column repair process will take more than 4 seconds. On the contrary, in case of row redundancy, only one page has to be programmed during the repair process.

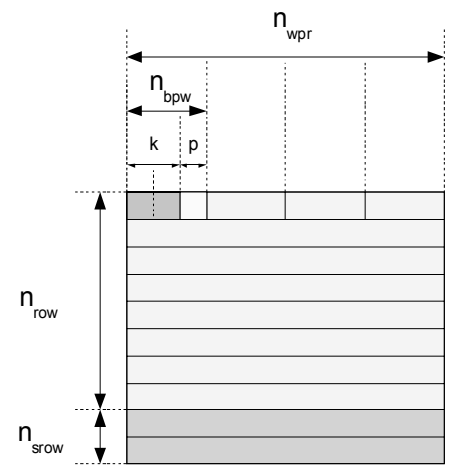

Figure 3 - Flash memory array modeling

In the rest of the paper, the following notations are used: each word is composed of $k$ information bits and $p$ parity bits with $n_{b p w}=k+p$ bits per word. $c c$ and $d c$ are defined as the error correction capacity and the error detection capacity associated to the error correcting code respectively. There are $n_{w p r}$ words per row (or page) and the array has $n_{\text {row }}$ normal rows and $n_{\text {srow }}$ spare rows. 
Reliability enhancement procedures always incorporate three steps:

- Error Detection (ED) - An error state is detected in a memory word. This process is usually performed by a control of the likelihood based on an error detection/correction code.

- Error Localization (EL) - Locations of the error bits in a memory word are determined. This step is performed using the capacity correction of an error correction code and/or a $\mathrm{V}_{\mathrm{T}}$ analysis.

- Retrieval Mechanism (RM) - When a bit is detected to be weak or in error, the information sent to the user must be corrected. Additionally, operation can be performed on the memory array to physically repair it (using redundancy), to refresh the data stored (using a refresh process) or to correct the information on the fly (using on-line detection/correction).

\subsection{Array Reliability with detection/localization procedures}

Three detection/localization procedures A, B and C are studied. As shown in table 2, procedures depend on the error correcting code implemented and so, on the number of parity bits added per word. Potentially, procedures A and $\mathrm{B}$ permit one error per word correction whereas the procedure $\mathrm{C}$ allows two errors correction.

\begin{tabular}{|c|c|c|c|c|}
\hline \multirow{2}{*}{\multicolumn{2}{|c|}{$\begin{array}{c}\text { Error correction } \\
\text { code implemented }\end{array}$}} & Procedure $\mathbf{A}$ & Procedure B & Procedure C \\
\hline & & Parity Code & $\begin{array}{l}\text { Hamming } \\
\text { Standard }\end{array}$ & $\begin{array}{l}\text { Extended } \\
\text { Hamming }\end{array}$ \\
\hline \multicolumn{2}{|c|}{$\mathbf{p}$} & 1 & $\log _{2}(k)+1$ & $\log _{2}(k)+2$ \\
\hline \multicolumn{2}{|c|}{ dc } & 1 & 1 & 2 \\
\hline \multicolumn{2}{|c|}{ cc } & 0 & 1 & 1 \\
\hline \multicolumn{2}{|c|}{ Detection } & \multicolumn{3}{|c|}{ Error correcting code (detection capacity) } \\
\hline \multirow{2}{*}{ 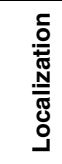 } & $\begin{array}{l}\text { One } \\
\text { error }\end{array}$ & $\mathrm{V}_{\mathrm{T}}$ analysis & $\begin{array}{c}\text { Error } \\
\text { correction } \\
\text { code } \\
\end{array}$ & $\begin{array}{c}\text { Error } \\
\text { correction } \\
\text { code } \\
\end{array}$ \\
\hline & $\begin{array}{c}\text { Double } \\
\text { error }\end{array}$ & - & - & $\mathrm{V}_{\mathrm{T}}$ analysis \\
\hline \multicolumn{2}{|c|}{$\begin{array}{l}\text { Total number of } \\
\text { correctable errors }\end{array}$} & 1 & 1 & 2 \\
\hline
\end{tabular}

\section{Table 2 - Detection/localization procedures}

When a word is read, the online ECC mechanism is used to detect errors. If error correction capacity of the ECC is sufficient, errors are automatically corrected and the result is sent to the user. If the error correction capacity is exceeded but error detection capacity is still sufficient, a $\mathrm{V}_{\mathrm{T}}$ analysis will determine weak bits in the slice $\left[\mathrm{V}_{\mathrm{L}}, \mathrm{V}_{\mathrm{H}}\right]$. Then, the following assumption is made: the weak bits discovered during the $\mathrm{V}_{\mathrm{T}}$ analysis are the failing bits that have not drifted enough to be hard errors. Consequently, if the number of weak bits in the word equals the number of error detected, the inversion of weak bits permits to recover the correct word. To illustrate that purpose, the procedure $\mathrm{C}$ is considered. In this case, the Extended Hamming Code is used, so 2 errors can be detected $(\mathrm{dc}=2)$ and only one can be corrected $(\mathrm{cc}=1)$. A read is performed on a word. If the word has a single error, the correction capacity is not exceeded. The ECC mechanism is able to transparently detect and correct the error. Now, if the word has two errors, the correction capacity is exceeded but not the detection capacity. The ECC mechanism is able to analyze the problem: two errors have been detected but not located. Then, a $\mathrm{V}_{\mathrm{T}}$ analysis is launched to locate weak bits. If two weak bits are found in the word, their values are inverted and the word is supposed to have been corrected. Table 2 summarizes detection and localization procedures A, B and C.

Reliability enhancements with the three detection/localization procedures are now analyzed. For that purpose, we enumerate reliable $\mathrm{V}_{\mathrm{T}}$ repartitions in a word:

- $\quad$ Procedure A: A memory word is correct if, for all cells, $\mathrm{V}_{\mathrm{T}}>\mathrm{V}_{\mathrm{N}}$ i.e. multiple bits may be weak but there is no error. Or, one cell has a $V_{T}$ in $\left[V_{L}, V_{N}\right]$ slice and all the others have $V_{T}>V_{H}$ i.e. one error is present due to one weak bit. It corresponds to the probability:

$$
\begin{aligned}
p_{\text {word }}^{A}= & \sum_{i=0}^{n_{b p w}} p_{w}\left(0,0, i, n_{b p w}-i\right) \\
& +p_{w}\left(0,1,0, n_{b p w}-1\right)
\end{aligned}
$$

- $\quad$ Procedure B: A memory word is correct if, for all cells, $\mathrm{V}_{\mathrm{T}}>\mathrm{V}_{\mathrm{N}}$ i.e. multiple bits may be weak but there is no error. Or, one cell has a $V_{T}<V_{N}$ and all the others have $V_{T}>V_{N}$ i.e. there is only one error. It corresponds to the probability:

$$
\begin{aligned}
p_{\text {word }}^{B} & =\sum_{i=0}^{n_{b p p w}} p_{w}\left(0,0, i, n_{b p w}-i\right) \\
& +\sum_{i=0}^{n_{b p w}-1} p_{w}\left(0,1, i, n_{b p w}-1-i\right)+\sum_{i=0}^{n_{b p w}-1} p_{w}\left(1,0, i, n_{b p w}-1-i\right)
\end{aligned}
$$

- $\quad$ Procedure C: A memory word is correct if, for all cells, $\mathrm{V}_{\mathrm{T}}>\mathrm{V}_{\mathrm{N}}$ i.e. multiple bits may be weak but there is no error. Or, one cell has $\mathrm{V}_{\mathrm{T}}<\mathrm{V}_{\mathrm{N}}$ and all the others have $V_{T}>V_{N}$ i.e. there is one error. Or, two cells have a $V_{T}$ in $\left[V_{L}, V_{N}\right]$ slice and all the others have $V_{T}>V_{H}$ i.e. there are two errors due to weak bits. It corresponds to the probability:

$$
\begin{aligned}
p_{\text {word }}^{C} & =\sum_{i=0}^{n_{b p w}} p_{w}\left(0,0, i, n_{b p w}-i\right) \\
& +\sum_{i=0}^{n_{b p w}-1} p_{w}\left(0,1, i, n_{b p w}-1-i\right)+\sum_{i=0}^{n_{b p w}-1} p_{w}\left(1,0, i, n_{b p w}-1-i\right) \\
& +p_{w}\left(0,2,0, n_{b p w}-2\right)
\end{aligned}
$$

There are $n_{w p r}$. $n_{\text {row }}$ words per array. Consequently, reliability expressions for pages and arrays without redundancy in procedures $\mathrm{A}, \mathrm{B}$ and $\mathrm{C}$ are obtained from (8), (9), (10):

$$
\begin{aligned}
& R_{\text {page }}^{i}=\left(p_{\text {word }}^{i}\right)^{n_{\text {wpr }}} \\
& R_{\text {ecc }}^{i}=\left(p_{\text {word }}^{i}\right)^{n_{\text {wpr }} \cdot n_{\text {row }}}
\end{aligned}
$$

where, $i$ is replaced by $\mathrm{A}, \mathrm{B}$ or $\mathrm{C}$. 


\subsection{Array Reliability with on-line repair procedure}

Online repair with row redundancy can be considered as a retrieval mechanism. As soon as an error is detected, the entire page is replaced with row redundancy if available. The corresponding reliability is given by:

$$
R_{\text {red }}^{i}=\sum_{k=0}^{n_{\text {sow }}} C_{n_{\text {row }}+n_{\text {sow }}}^{k}\left(R_{\text {page }}^{i}\right)^{n_{\text {row }}+n_{\text {sow }}-k}\left(1-R_{\text {page }}^{i}\right)^{k}
$$

\subsection{Array Reliability with mixed repair and ECC procedure}

In reality, when all redundancy rows have been used, the error detection/localization system still corrects errors and the memory continues to be reliable. In other words, the reliability expression (13) is used for memories whose number of pages in error is at least equal to the number of spare rows. Assuming $n_{\text {srow }}>0$, the probability that some redundancy is still available is expressed by:

$$
p_{n_{\text {sow }}}^{i}=\sum_{k=0}^{n_{\text {sow }}-1} C_{n_{\text {row }}+n_{\text {srow }}}^{k}\left(R_{\text {page }}^{i}\right)^{n_{\text {row }}+n_{\text {sow }}-k}\left(1-R_{\text {page }}^{i}\right)^{k}
$$

With this procedure, the reliability of the array is:

$$
R_{\text {red }+e c c}^{i}=\left(1-p_{n_{\text {srow }}}^{i}\right) \cdot R_{\text {ecc }}^{i}+p_{n_{\text {srow }}}^{i}
$$

\section{Results and Discussion}

The figure 4 is a comparison of the reliability between a standard eFlash array and eFlash arrays with detection/localization procedures (12) developed in the section 4.2 after $10^{5}$ program/erase cycles. The $\mathrm{V}_{\mathrm{T}}$ limits have been chosen as follow: $\mathrm{V}_{\mathrm{L}}=-1 \mathrm{~V}, \mathrm{~V}_{\mathrm{N}}=0 \mathrm{~V}$ and $\mathrm{V}_{\mathrm{H}}=$ $1 \mathrm{~V}$. There are $n_{\text {row }}=1024$ rows and $n_{w p r}=64$ words per row. All curves are normalized in time by the Mean Time To Failure (MTTF) of the standard array noted MTTF $_{\text {standard. }}$. Model parameters have been calibrated on a $180 \mathrm{~nm}$ eFlash technology, based on measurements performed on samples of a $2 \mathrm{Mb}$ memory.

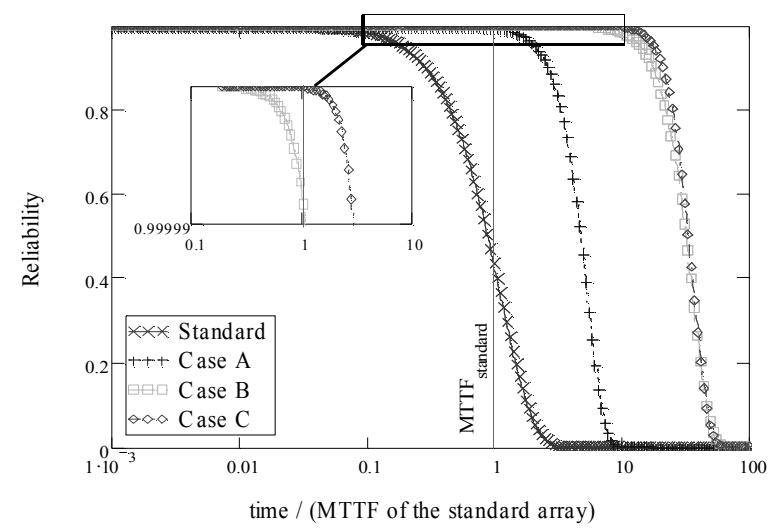

Figure 4 - Reliability of 2Mbits arrays using detection/localization procedures only

With the procedure A, only one error can be corrected using a $\mathrm{V}_{\mathrm{T}}$ analysis. This scheme can correct one weak failing bit per word. As illustrated in the table 3, the MTTF is improved by a factor 4.67 with this procedure in comparison with a standard array. However, the hard failing bits are not reachable. Consequently, the reliability improvement is lesser than with the procedure $\mathrm{B}$ where one weak failing or one hard failing bit can be corrected thanks to the Hamming Correcting Code. In the procedure B, the MTTF is improved by a factor 25.1 in comparison with a standard array. Namely, if a memory has a MTTF equal to 1 year, then in procedures A and B, the MTTF will be respectively improved to 4.67 years and 25.1 years. In the procedure $\mathrm{C}$, there is no noticeable improvement of the reliability compared to the procedure $B$ even if an Extending Hamming Code and $\mathrm{V}_{\mathrm{T}}$ analysis are used to correct up to two errors: the MTTF gain is only 26.3. Nevertheless, the reliability decrease occurs later in the procedure $\mathrm{C}$ than in the procedure $\mathrm{B}$. This phenomenon is observed focusing on the beginning of the curve decrease as shown in the figure 4. For instance, at time $M T T F_{\text {standard, }}$ $56.3 \%$ of the standard arrays would have failed. In procedures A, B and C, only 6263, 7.2 and 0.08 parts per million (ppm) would have failed respectively. The two decades difference between procedures $\mathrm{B}$ and $\mathrm{C}$ may justify the adoption of the procedure $\mathrm{C}$ for products needing high reliability rates.

The impact of the erratic bits ratio on the reliability scheme is low. Indeed, if the ratio is increased by a factor $10^{2}$, then, $9.7 \mathrm{ppm}, 0.11 \mathrm{ppm}$ would have failed in procedures B and C at time $M T T F_{\text {standard. }}$

2Mbits eFlash array with distinct word lengths have been reported in the table 3. Array overheads and MTTF gains are presented. MTTF gains are independent of the number of cycles due to the logarithmic dependence of $n_{\text {cycles }}$ in our cell model. Our cost function is defined as the ratio between the array overhead and the logarithm of the MTTF gain. When the word length is increased the MTTF gain is reduced but the overhead impact decreases far more rapidly. In consequence, the cost function decreases. Array requiring moderate reliability improvement for a very low

\begin{tabular}{|c|c|c|c|c|c|c|c|c|c|}
\hline & \multicolumn{3}{|c|}{ Procedure A } & \multicolumn{3}{|c|}{ Procedure B } & \multicolumn{3}{|c|}{ Procedure C } \\
\hline Max. Cor. & \multicolumn{3}{|c|}{1} & \multicolumn{3}{|c|}{1} & \multicolumn{3}{|c|}{2} \\
\hline $\begin{array}{c}\text { Constant } \\
\text { Parameters }\end{array}$ & \multicolumn{9}{|c|}{$\mathrm{n}_{\text {row }}=1024, \mathrm{n}_{\mathrm{wpr}}=64, \mathrm{~V}_{\mathrm{L}}=-1, \mathrm{~V}_{\mathrm{N}}=0, \mathrm{~V}_{\mathrm{H}}=1$} \\
\hline $\mathbf{k}$ & 32 & 64 & 128 & 32 & 64 & 128 & 32 & 64 & 128 \\
\hline$p$ & 1 & 1 & 1 & 6 & 7 & 8 & 7 & 8 & 9 \\
\hline $\mathbf{n}_{\text {wpr }}$ & 64 & 32 & 16 & 64 & 32 & 16 & 64 & 32 & 16 \\
\hline $\begin{array}{c}\text { Array } \\
\text { Overhead } \\
(\%)\end{array}$ & 3.1 & 1.6 & 0.8 & 18.7 & 10.9 & 6.2 & 21.9 & 12.5 & 7.0 \\
\hline MTTF Gain & 4.67 & 3.80 & 3.16 & 25.1 & 23.4 & 20.9 & 26.3 & 24.0 & 21.4 \\
\hline $\begin{array}{c}\text { Cost } \\
\text { Overhead/ } \\
\text { log(MTTF } \\
\text { gain) }\end{array}$ & 4.6 & 2.8 & 1.6 & 13.4 & 8.0 & 4.7 & 15.4 & 9.1 & 5.3 \\
\hline $\begin{array}{l}\text { \# Defective } \\
\text { arrays at } \\
\text { MTTF }_{\text {standard }} \\
\text { (ppm) }\end{array}$ & 6263 & 12663 & 17637 & 7.2 & 12.6 & 23.4 & 0.08 & 0.2 & 0.59 \\
\hline
\end{tabular}
cost may adopt the procedure A. On the contrary, to be fully reliable, the procedures $\mathrm{B}$ or $\mathrm{C}$ should be adopted.

Table 3 - Summary of 2 Mbits arrays using detection/localization procedures only 
The figure 5 shows a reliability comparison between a standard array and arrays with mixed detection/localization procedures (A or B) and the online repair developed in the section 4.4 after $10^{5}$ program/erase cycles. The $\mathrm{V}_{\mathrm{T}}$ limits have been chosen as follow: $\mathrm{V}_{\mathrm{L}}=-1 \mathrm{~V}, \mathrm{~V}_{\mathrm{N}}=0 \mathrm{~V}$ and $\mathrm{V}_{\mathrm{H}}=$ $1 \mathrm{~V}$. There are $n_{\text {row }}=1024$ rows and $n_{w p r}=64$ words per row. The number of row redundancy is a parameter.

At first look, the online repair makes the reliability slope sharper. In table 4 , we have reported the number of defective arrays at time $M T T F_{\text {standard }}$. This number becomes zero as soon as some redundancy is added. This observation is independent of the detection/localization procedures used. Thanks to table 4 , we can note that the procedure A with 2 rows results in less defective arrays after $M T T F_{\text {standard }}$ than the procedure $\mathrm{B}$ with 0 rows. Consequently, the array becomes very reliable at time $M T T F_{\text {standard }}$ adding the online repair. The figure 5 shows also that the MTTF gain is increased adding few rows. But, the improvement reduces slowly with each new row. In the table 4 , this is traduced by a decrease slow down of the cost function. As a result, only a low number of rows are useful. The procedure A associated with online repair would be a very good choice to manage reliability at a reduced array overhead cost.

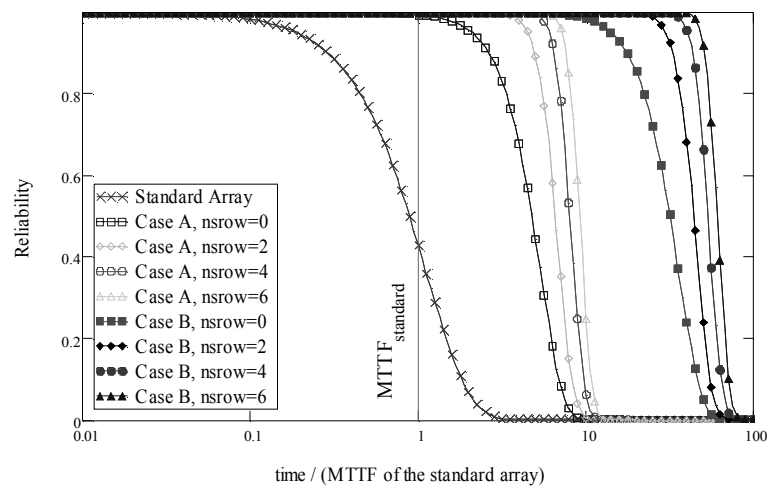

Figure 5 - Reliability of 2 Mbits arrays using mixed detection/localization and online repair procedures

\begin{tabular}{|c|c|c|c|c|c|c|c|c|}
\cline { 2 - 10 } \multicolumn{1}{c|}{} & \multicolumn{4}{c|}{ Procedure A } & \multicolumn{5}{c|}{ Procedure B } \\
\hline Max. Cor & \multicolumn{4}{c|}{1} & \multicolumn{3}{c|}{1} \\
\hline $\begin{array}{c}\text { Constant } \\
\text { parameters }\end{array}$ & \multicolumn{3}{c|}{$\mathrm{k}=32, \mathrm{n}_{\text {row }}=1024, \mathrm{n}_{\text {wpr }}=64, \mathrm{~V}_{\mathrm{L}}=-1, \mathrm{~V}_{\mathrm{N}}=0, \mathrm{~V}_{\mathrm{H}}=1$} \\
\hline $\mathbf{p}$ & \multicolumn{3}{|c|}{1} & \multicolumn{5}{c|}{6} \\
\hline $\mathbf{n}_{\text {srow }}$ & 0 & 2 & 4 & 6 & 0 & 2 & 4 & 6 \\
\hline $\begin{array}{c}\text { Array } \\
\text { Overhead (\%) }\end{array}$ & 3.1 & 3.3 & 3.5 & 3.7 & 18.7 & 19.0 & 19.2 & 19.4 \\
\hline MTTF Gain & 4.67 & 6.31 & 7.76 & 8.91 & 25.1 & 41.7 & 50.1 & 57.5 \\
\hline $\begin{array}{c}\text { Cost Overhead// } \\
\text { Log(MTTF Gain) }\end{array}$ & 4.6 & 4.1 & 3.9 & 3.9 & 13.4 & 11.7 & 11.3 & 11 \\
\hline $\begin{array}{c}\text { \# Defective } \\
\text { arrays at } \\
\text { MTTF } \\
\text { (ppm) }\end{array}$ & 6263 & 0.1 & $\sim 0$ & $\sim 0$ & 7.2 & $\sim 0$ & $\sim 0$ & $\sim 0$ \\
\hline
\end{tabular}

Table 4 - Summary of 2 Mbits arrays reliability using mixed detection/localization and online repair procedures.

\section{Conclusion}

In this paper, an eFlash array reliability model has been developed. We have clearly shown that by mixing different reliability techniques (ECC, redundancy, $\mathrm{V}_{\mathrm{T}}$ analysis), high reliability improvement can be reached. Our work is based on the fact that eFlash memories are analog devices; analog information can be extracted from cells for reliability purpose. The $\mathrm{V}_{\mathrm{T}}$ analysis was proven to be a powerful method with a low additional cost in order to localize errors when ECC can only detect it. The online redundancy has also been studied. This method allows reducing the number of defective chips after $\mathrm{MTTF}_{\text {standard. }}$ For a given technology and a given eFlash memory architecture, this work helps designer to adopt the most adapted scheme in order to reach a defined ppm and MTTF objective. In our future work, we will focus on the implementation of such schemes. A modified eFlash memory architecture and a logical memory wrapper to perform online repair, ECC and $\mathrm{V}_{\mathrm{T}}$ analysis will be presented.

\section{References}

[1] Semiconductor Industry Association (SIA), "International technology roadmap for semiconductors (ITRS)", http://www.sia-online.org/home.cfm, 2005.

[2] C. T. Huang, J. C. Yeh, R. F. Huang, C. W. Wu, P. Y. Tsai, A. Hsu and E. Chow, "A built-in self-repair scheme for semiconductor memories with 2-D redundancy", in Proc. Int. Test Conf., p.393, 2003.

[3] M. Choi, N. Park, F. Lombardi, Y. B. Kim and V. Piuri, "Optimal Spare Utilization in Repairable and Reliable Memory Cores", in Proc. Of Int. Work. On Mem. Tech. and Design, p.64, 2003.

[4] C-H. Chen, Y-Y. Hsaio, C-W. Wu, "A Built-In Self-Repair Scheme for NOR-type Flash Memory", in Proc. of the VLSI Test Symp., p.114-119, 2006.

[5] C-L. Su, Y-T. Yeh, C-W. Wu ,"An Integrated ECC and Redundancy Repair Scheme for Memory Relibability Enhancement", in Proc. of the Int. Symp. Defect and Fault Tolerance in VLSI Systems, p.81-89, 2005.

[6] C. Wickman, D. G. Elliott, and B. F. Cockburn, "Cost model for large file memory DRAMs with ECC and bad block marking", in Proc. of the Int. Symp. Defect and Fault Tolerance in VLSI Systems, p.319, 1999.

[7] J.M. Portal, H. Aziza, D. Née, "Eeprom memory: threshold voltage built in self diagnosis", in Proc. of the Int. Test Conf., p.23-28, 2003.

[8] Y. Furuta, T. Okumura, "Non-volatile memory refresh control circuit", US Patent $n^{\circ} 4218764,1980$.

[9] La Rosa, "One bit error correction in a chain of bits", EP Patent $n^{\circ} 1109321$ A1, 2001.

[10] H. P. Belgal, N. Righos and al., "A new reliability model for post-cycling charge retention of Flash memories", in Proc. of the Annual Int. Rel. Phys. Symp., p.7-20, 2002.

[11] A. Hoefler, J. M. Higman and al., "Statistical modeling of the program/erase cycling acceleration of low temperature data retention in floating gate non-volatile memories", in Proc. of the Annual Int. Rel. Phys. Symp., p.60-66, 2002.

[12] R. Degreave, F. Schuler and al., "Analytical percolation model for predicting anomalous charge loss in Flash memories", in Trans. On Elect. Dev., p.1392-1400, 2004.

[13] J. Harthong, "Probabilities and statistics", Ed. Diderot, 1980. 